\title{
O cênico no Protágoras
}

\author{
ROBERTO BOLZANI FILHO \\ Departamento de Filosofia \\ Faculdade de Filosofia, Letras e Ciências Humanas \\ Universidade de São Paulo
}

RESUMO: O artigo pretende examinar função e sentido do aspecto cênico presente em alguns momentos do diálogo Protágoras de Platão, para concluir que tal aspecto, formal, colabora no estabelecimento do próprio conteúdo do diálogo.

PALAVRAS-CHAVE: Socratismo; Sofística; diálogo.

É notório que, além de filósofo fundamental, Platão foi escritor excepcional. Seus diálogos exibem, a um tempo, conteúdo filosófico de grande riqueza e momentos de intenso prazer à leitura, sendo mesmo possível passar ao largo de questões de doutrina, para os ler como obras literárias e deleitar-se com a vivacidade das personagens, o fino humor do pastiche de figuras históricas ou a dramaticidade das situações. Esse fato, contudo, não nos deve conduzir a uma perigosa ilação, a de que tais diálogos consistem de "conteúdos" previamente definidos e elaborados in mentem auctoris que, só então, recebem sua "forma" dialogada, como um acréscimo que se explicaria por uma opção, talvez caprichosa, de seu criador. Vê-los assim, hoje com freqüência se reconhece, é, talvez, menos do que compreendêlos pela metade, deixar de compreendê-los por completo. É perder de vista suas intenções e os motivos que os animam. É, também, imaginar como seus destinatários supostos membros de uma "comunidade filosófica" que saberá, munida dos meios adequados, separar deles o que neles há de "filosófico" e o que neles há de "literário".

Dentre os diálogos de Platão, o Protágoras, pela importância dos temas que veicula, por sua força pictórica e elaboração sofisticada, é dos que melhor ilustram essa relação intrínseca entre $o$ que se quer dizer e como se deve dizê-lo. Considerado freqüentemente como

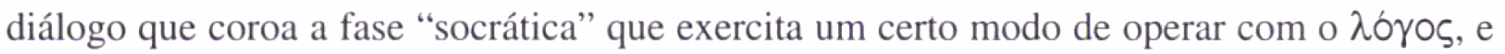
como momento de passagem para diálogos que haverão de empreender uma rearticulação já genuinamente platônica da herança do socratismo, o Protágoras é, certamente, um dos mais belos produtos da escrita de Platão. Este texto gostaria de analisar algumas de suas páginas à luz dessa aliança profunda entre reflexão filosófica e construção literária.

A singularidade desse diálogo, em face dos que provavelmente o antecedem, pode ser bem captada de comentário do professor José Cavalcante de Souza: "todavia, enquanto 
nos citados diálogos, excetuando-se o Hípias Menor, a discussão parte da pergunta 'Que é tal virtude?', e se desenvolve toda em torno das sucessivas respostas apresentadas, no Protágoras a questão 'Que é a virtude?' só aparece no próprio desfecho do debate (Prot. 360e), e pode-se dizer, como uma das suas principais consequiências, e mesmo como o seu grande resultado positivo, a indicar ironicamente a vitória da argumentação socrática, indagadora da essência, sobre a terrível sabedoria relativista do sofista de Abdera. Essa aparente inferioridade doutrinária do diálogo, que termina onde aqueles outros começam, significa na verdade uma capacidade adulta de remontar além dos dados mais ou menos claros de uma doutrina ou de um pensamento já desabrochados, e de perscrutar a zona obscura dos seus começos. O relato das conversas de Sócrates com os jovens freqüentadores dos ginásios atenienses revela a assimilação inteligente de uma dialética em plena fase de expansão e de amadurecimento, empenhada em orientar espíritos dóceis através das primeiras dificuldades do conhecimento das coisas humanas. Seu confronto com o mais antigo e o mais venerável dos sofistas denota uma visão profunda de duas forças espirituais que se confundiam aos olhos do grande público, e que, entretanto, divergiam radicalmente. Para caracterizá-las devidamente, era preciso um diálogo de proporções mais amplas e de estrutura mais sólida e complexa, onde os temas socráticos pudessem surgir do próprio impacto da presença atuante e das formais pretensões dos sofistas" (Cavalcante de Souza, 1969, p.70-71).

Esta passagem faz várias observações importantes, pois a partir dela o Protágoras emerge como momento de confronto entre duas mentalidades - duas "forças espirituais" que se expressavam de modo semelhante, ou melhor, no mesmo terreno - o discurso - e com vistas aos mesmos fins: propor uma $\pi \alpha \imath \delta \varepsilon i \alpha$, uma forma de educação. Perscrutar a mentalidade sofístico-protagoriana, dela discernindo com exatidão os traços fundamentais que delineiam o ensino socrático, se faz, portanto, imperativo, pois, "aos olhos do grande público", Sócrates e os sofistas aparecem unidos pela atitude comum do exercício permanente e, talvez, estranho e suspeito, de seus $\lambda$ o $\gamma o r$, tornando-se todos, indistintamente, "hábeis no falar". É para este "grande público", certamente impressionado pelo brilhante e poderoso efeito cômico-crítico das Nuvens de Aristófanes, onde Sócrates, como qualquer sofista, ensina por dinheiro (vs. 95-100) a "tornar forte o argumento fraco", a "tornar justo o argumento injusto" (vs. 110-115), que Platão escreve o diálogo.

Vão no mesmo sentido as observações de A. Koyré, referindo-se à personagem do jovem Hipócrates, que pede a Sócrates que o ajude a tornar-se aluno de Protágoras, fornecendo, assim, a ocasião para o diálogo: "Hipócrates procura coisas novas sem, no entanto, saber bem o que quer. E é por isso que nos não devemos admirar demasiado de o ver pedir a Sócrates que o recomende aos sofistas (os leitores-ouvintes de Platão sem dúvida que saborearam a ironia da situação). É claro que Hipócrates, como o ateniense médio, em geral, está longe de saber distinguir entre socratismo e sofística. Parecem-lhe muito próximos. Não se opõem ambos à moral tradicional? Não fazem ambos a crítica do senso comum? Não contêm ambos um apelo ao novo? É essa também a razão pela qual Sócrates aceita levá-lo a Protágoras: justamente para lhe oferecer o confronto das duas doutrinas; para lhe permitir escolher. O diálogo teria podido - ou devido - chamar-se: Hipócrates na encruzilhada dos caminhos" (Koyré, 1979, p. 30-31). Eis aí mais uma denominação para o "grande público" a que o diálogo se endereça: o "ateniense médio", neste caso, o jovem 
ateniense abastado e ansioso por adquirir $\pi \alpha 1 \delta \varepsilon^{\prime} i \alpha$, de bom nascimento e, acima de tudo, partícipe potencial das decisões a respeito do destino da $\pi \dot{o} \lambda \iota \varsigma$. Importa destacar ainda outra idéia: o leitor dos diálogos de Platão seria um "leitor ouvinte", isto é, alguém que sabe vê-los também como obras dramáticas que são: "toda a gente reconhece que os diálogos de Platão são composições dramáticas admiráveis onde, diante de nós, as idéias e os homens que as trazem se chocam e confrontam. Toda a gente, ao ler um diálogo de Platão, sente que ele poderia ser dramatizado, levado à cena" (Koyré, 1979, p. 12-13).

Porque procura investigar o que se passaria por detrás do ensino professado pelos sofistas, os valores e intenções que o norteariam, este diálogo - como também o Górgias é, digamos, lógica e filosoficamente prévio àqueles que, como os dois Hípias, mostram a interrogação socrática já em ação, criticamente, contra um de seus representantes. Assim, se a pergunta "o que é a virtude" só surge ao final do diálogo, é porque se trata de mostrar ao leitor que os impasses a que levam as tentativas de conversação entre Sócrates e Protágoras são inevitáveis, pois, antes de tudo, teria sido necessário fazer aquela simples mas fundamental pergunta, que a mentalidade sofística, aqui representada paradigmaticamente por Protágoras, não pode ou não quer valorizar. Nesse confronto, expresso em termos doutrinais no tema da relação entre virtude e ciência, encontra-se também outro, fundamental, que o diálogo vai desenvolvendo paralelamente: o do conflito entre duas concepções a respeito da melhor utilização do $\lambda \delta \gamma o \zeta$, com a preferência socrática pelo discurso breve, de perguntas e respostas, e a insistência protagoriana no discurso contínuo e longo. Ora, este tema, em nada inferior ao anterior em importância e, em verdade, dele inseparável - exprimem ambos duas diferentes facetas de duas diferentes mentalidades -, parece ser explorado por Platão por meio de aspectos visuais presentes na narrativa de Sócrates a um amigo sobre o ocorrido. São esses elementos cênicos do diálogo que este texto pretende comentar ${ }^{1}$.

A cena é a casa de Cálias, que hospeda Protágoras e, além dele, Hípias e Pródico. Sócrates e Hipócrates acabam de entrar e, da porta, Sócrates descreve o que vêem, qual espectadores num teatro, como sugere sua afirmação após a descrição: "nós então, logo que entramos, depois de conversar um pouco e contemplar essas cenas ( $\tau \alpha \hat{\tau} \tau \alpha \delta 1 \alpha \theta \varepsilon \alpha \sigma o ́ \mu \varepsilon v o l)$, aproximamo-nos de Protágoras" (316a)². Vejamos os momentos mais importantes: "quando

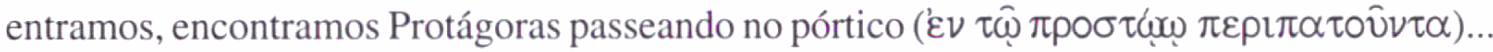
Os que estavam atrás destes (oî ǒ $\pi \imath \sigma \theta \varepsilon \nu$ ) acompanhavam escutando o que se dizia. Via-se que eram estrangeiros, que Protágoras traz de cada uma das cidades por onde passa, encantando-os com sua voz ( $\tau$ 斤 $\phi \omega \nu$ ก̣) como Orfeu e eles, encantados, acompanhavam sua

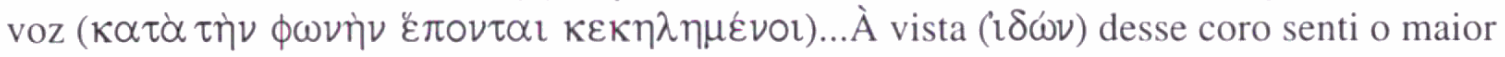
prazer $(\mu \dot{\alpha} \lambda \iota \tau \tau \alpha \ldots \eta \eta \eta \emptyset \theta \eta \nu)$. Quanta precaução tomavam para que em momento algum ficassem na frente ( $\varepsilon \nu \tau \hat{\omega} \pi \rho \delta \sigma \theta \varepsilon \nu$ ) de Protágoras e, quando este se voltava com os que o cercavam, os de trás que os ouviam entreabriam suas fileiras e, fazendo um círculo,

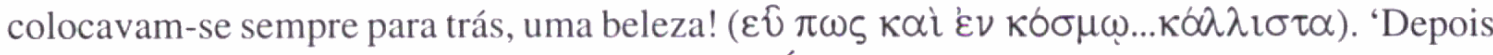
dele, reconheci', como diz Homero, Hípias de Élide, sentado no pórtico oposto, num trono

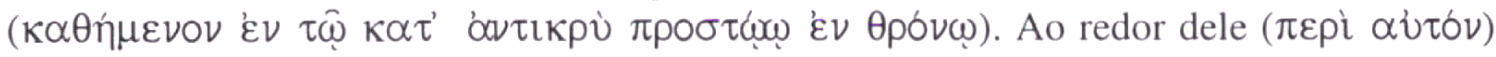
estavam sentados em bancos ('ยสì ßóx $\theta \omega \nu)$... 'também avistei Tântalo', pois estava na cidade também Pródico de Céos. Estava em uma peça que antes Hipônico utilizava como

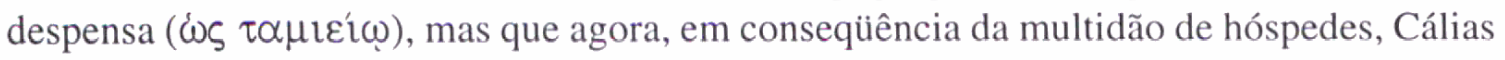


também esvaziara e fizera dele um quarto para estrangeiros. Pródico estava ainda deitado ( $\varepsilon$ $\tau \iota \kappa \propto \tau \varepsilon \kappa \varepsilon \imath \tau o$ ), envolto em umas peles e cobertas, bem numerosas, como se via. Ao lado

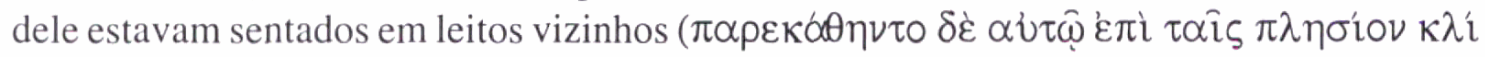

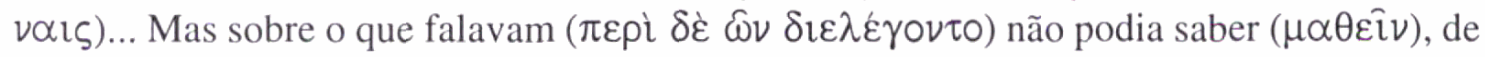
fora, embora desejasse vivamente ouvir Pródico, pois me parece um homem superiormente

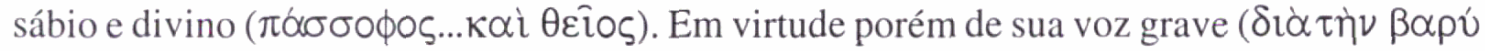
$\tau \eta \tau \alpha \tau \eta \hat{\varsigma} \phi \omega \nu \eta \hat{\varsigma})$, uma espécie de zumbido que se formava no quarto tornava as palavras

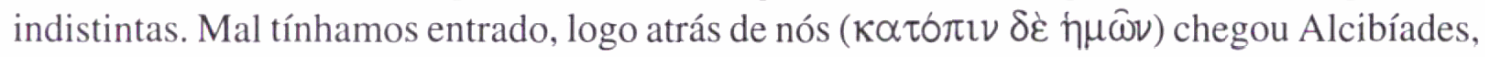
o belo, como tu dizes e eu concordo, e Crítias, filho de Calescro" (314e-316a).

A descrição de Sócrates é feita de sorte a ressaltar aspectos visuais e, de modo geral, sensíveis, com tal riqueza de pormenores, que ao leitor se impõe a pergunta a respeito de sua função. Sem dúvida, o cortejo de Protágoras, a posição majestosa de Hípias e o desleixo sem cerimônia de Pródico podem e devem ser interpretados como forma de simbolizar a fama e respeito de que gozam esses sofistas junto à aristocracia ateniense, bem como o privilégio que possuem de aglutinar audiências na condição de mestres superiores. Mas o poder de sugestão dessas imagens vai muito além disso.

Note-se, por exemplo, a relação espacial que se estabelece entre os sofistas e seus seguidores. No caso de Protágoras, andando de um lado a outro do aposento com alguns visitantes, seguem-nos simetricamente os discípulos. A preocupação destes em fazer a volta ao grupo, de modo a nunca se pôr à frente do sofista, além de cômica, denota quão importante e impressionante é a forma sensivel do evento, e Sócrates registra o prazer visual que a ordem ou harmonia ( $\varepsilon \nu \kappa \delta \sigma \mu \omega$ ) desse cortejo nele produz. Ao mesmo tempo, encarregados de produzir tal efeito cosmético, os discípulos, provavelmente, não tinham muita atenção para prestar ao que se dizia...O que não parece muito grave, pois, em verdade, eram atraídos, diz Sócrates, pela voz de Protágoras, pelo som que ouvem, como se encantados por Orfeu. E nada se comenta sobre o conteúdo da conversa de Protágoras com seus acompanhantes, impondo-se com tanta veemência ao espectador o aspecto visual da situação.

$\mathrm{O}$ destaque conferido por Sócrates à beleza e simetria da cena ganha em significado quando nos recordamos do início da Apologia: introduzindo sua defesa, Sócrates pede que não seja tido por um "orador" ('́nं $\tau \omega \rho)$ - ao menos, não no mesmo sentido daqueles que

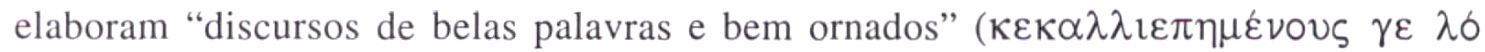

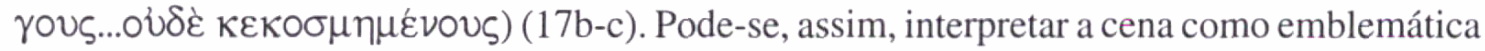
da aliança entre sofística e retórica ( $\kappa \delta \sigma \mu o \varsigma$, sabe-se, foi termo caro também a Górgias) ${ }^{3}$. E o que a passagem da Apologia sugere para a interpretação de nosso trecho do Protágoras é que, se a ordem e harmonia sensíveis poderiam em princípio parecer ornamentais, em nossa cena se destacam, aos olhos de Sócrates, como fundamentais - como, por assim dizer, constitutivas do "saber" do sofista.

Se Protágoras se mantém sempre à frente de seus seguidores, Hípias está sempre acima dos seus, sentado em um trono, como um rei, enquanto os ouvintes acomodam-se em bancos. Do alto de sua propalada "polimatia", de seu múltiplo saber, e no centro de um círculo de acólitos, Hípias distribui respostas e exibe sua superioridade, discorrendo sobre fenômenos celestes. Sócrates pouco se detém em Hípias; é mesmo pouco importante sua participação no diálogo, por isso não haverá motivo e lugar suficientes para a atuação da 
personagem ao mesmo tempo arrogante e parva do Hipias Maior. Não parece ter grande importância o fato de sabermos de que fala Hípias, e o próprio Protágoras observará com malícia a inutilidade desses assuntos de astronomia (318e). O confronto de Sócrates não é com ele, que nada terá a dizer sobre os temas que realmente importam. No entanto, mais uma vez a posição espacial é sugestiva: localizado no pórtico oposto ao de Protágoras, o sofista de Élis comparece para simbolizar a rivalidade entre concorrentes que estão em busca de um mesmo "mercado" e que devem, portanto, operar com certa distância. De fato, Protágoras, quando percebe o interesse de Sócrates e Hipócrates, não perde a chance de se exibir a Hípias e Pródico (317b-d); Hípias, por sua vez, procura uma oportunidade para participar do debate, provavelmente cansado do papel de coadjuvante, mas é impedido - em situação, decerto, pouco convencional e, por isso mesmo, sintomática - pelo jovem Alcibíades, tão inoportuna é sua intervenção (347a-b).

O caso de Pródico é diferente. De início, note-se o segundo plano de sua posição na cena: instalado numa antiga despensa, é pouco visível a Sócrates e quase inaudível. Seus ouvintes não o olham de baixo, pois estão, como ele, em camas; é ele quem deve olhar para cima, pois está deitado e os discípulos, sentados. Sócrates demonstra grande curiosidade em saber sobre que fala Pródico, que, ao contrário de Protágoras, possui voz pouco atraente, grave, pesada, certamente sem encanto e, talvez, dotada de $\alpha \kappa o \sigma \mu i ́ \alpha$. Mas esta voz inadequada tem, para Sócrates, algo que dizer. É preciso recordar que o mestre de Platão, a julgar pela data dramática do diálogo, é relativamente jovem, se comparado a Protágoras e os outros sofistas (314b). A personagem reflete, de modo verossímil, esse estágio de sua vida intelectual. Suas relações com Pródico são complexas: ainda fascinado pelo exercício

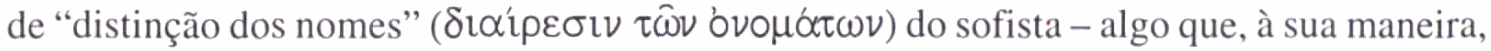
fará na maturidade -, sabe já discernir quando esse hábito de Pródico ameaça prejudicar o andamento da investigação (cf. 358a) ${ }^{4}$. Mesmo assim, à porta, refere-se a Pródico como sábio, afirmação que o diálogo mostrará não ser gratuita: se as intervenções desse sofista exibem algumas distinções certamente cômicas, em certo momento ele parece, como se verá, acertar em algo profundo. Sua presença na cena, sensivelmente inferior, simboliza essa deferência.

A posição espacial dos protagonistas será, então, expressiva de certo conteúdo que o diálogo nos quer comunicar, pois essa posição, qualitativamente diferenciada, indica outra distinção, também qualitativa, na relação entre o sofista e seu ouvinte. Noutras palavras, Platão quer nos dizer que o interlocutor de Sócrates, Protágoras, o sofista, concebe a $\pi \alpha$ เ $\delta \varepsilon \dot{\imath}$ $\alpha$ como transmissão de um "saber", que professa com a chancela da $\delta 6 \xi \alpha$ - "todos louvam o homem", diz Hipócrates a Sócrates (310e) -, a um aluno ou ouvinte que certamente deve acolher o seu $\lambda$ b $\gamma \circ \varsigma$ como a um veículo de superioridade inconteste.

A importância do elemento cênico e da posição espacial dos "atores" se faz mais evidente, se observamos o início do texto, quando Hipócrates procura Sócrates e lhe pede que o apresente a Protágoras (310b e segs.). Em sua ansiedade juvenil, Hipócrates chegou ainda de madrugada e, no escuro, diz Sócrates, "apalpando o leito, sentou-se junto a meus

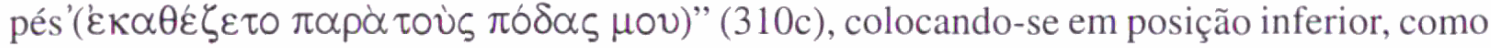
um discípulo diante do mestre. Sócrates não tardará em desfazer essa situação: "Não vamos lá agora, meu caro, pois ainda é cedo; mas levantemo-nos ( $\varepsilon \xi \alpha \nu \alpha \sigma \tau \tilde{\omega} \mu \varepsilon v$ ) e vamos ao 


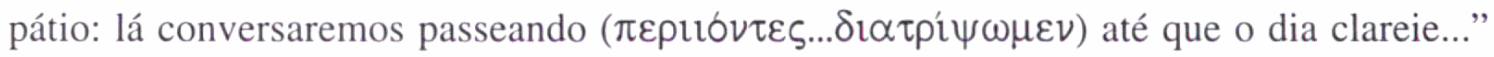
(311a). Segue-se um pequeno diálogo dentro do diálogo, onde encontramos o "método" socrático de perguntas e respostas breves - o contraponto ao "ensino" do sofista. Seu resultado não é a posse de nenhuma verdade, mas sim refrear o cego entusiasmo do jovem, que, incapaz de se justificar - movido que era por ingênua aceitação da $\delta \delta \xi \alpha$-, agora irá, com Sócrates, "examinar" ( $\sigma \kappa о \pi \omega ́ \mu \varepsilon \theta \alpha, 314 b)$ a natureza do suposto saber de Protágoras. A intenção "desnorteadora" da conversa sugere-se já na caminhada circular ( $\pi \varepsilon \rho ı$ lı $\nu \tau \varepsilon \varsigma)$ que ambos fazem pelo pátio.

Ora, neste episódio introdutório que antecede o encontro com o sofista, a posição espacial dos interlocutores é de igualdade. E, ao que parece, essa será para Sócrates a correta relação que devem sustentar entre si quaisquer interlocutores, participantes de uma troca de $\lambda$ ơoร, em busca de $\pi \alpha i \delta \varepsilon i \alpha$. Assim, a extensa conversação entre os dois protagonistas se dará num cenário modificado de maneira sintomática: “ 'Querem então', acrescentou Cálias, 'que organizemos uma sessão para que conversem sentados ( $\kappa \alpha \theta \varepsilon \zeta \zeta \mu \varepsilon v o r ~ \delta 1 \alpha \lambda \varepsilon \dot{\varepsilon} \eta \sigma \theta \varepsilon)$ ?' Decidiram que convinha. E todos nós contentes, na expectativa de ouvir homens sábios,

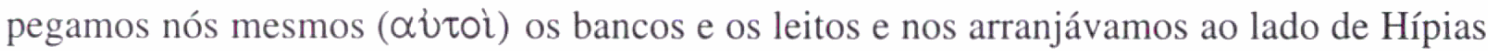

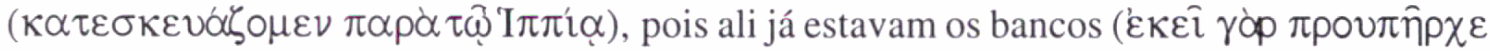
$\tau \dot{\alpha} \beta \alpha ́(\theta p \alpha)$. Nisso chegavam Cálias e Alcibíades, que traziam Pródico e os que estavam com

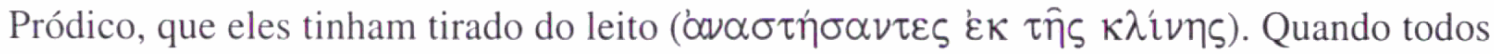

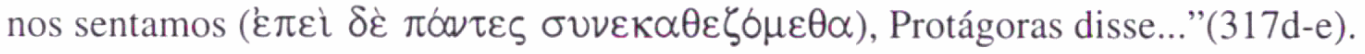

Platão nos dá aqui indicações importantes. Todos, os que falam e os que ouvem, estão "sentados juntos" ( $\sigma \nu v \varepsilon \kappa \alpha \theta \varepsilon \zeta \zeta \mu \varepsilon \theta \alpha)$, todos em bancos, que eles mesmos pegam. E, se é ao lado de Hípias que se acomodam, é apenas porque os bancos já estavam ali, não por qualquer deferência ao propalado saber do sofista. Não há mais nenhuma distinção qualitativa do espaço ocupado. Teremos, então, o que o texto chama algumas vezes de "reunião",

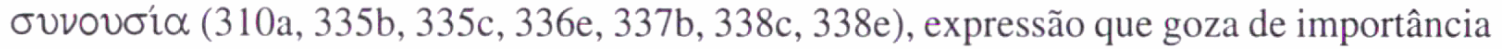
significativa na concepção socrática de diálogo que irá se desdobrar no decorrer da conversação. Esta se dará, digamos, num clima de igualdade e reciprocidade - a começar pela própria configuração sensível do evento.

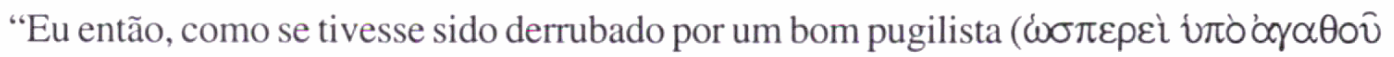
$\pi \cup ́ \kappa \tau o v ~ \pi \lambda \eta \gamma \varepsilon i ́(\varsigma) . . . "(339 e)$ - eis como Sócrates relata seu estado, após uma longa fala de Protágoras. Essa analogia não é gratuita, pois o próprio sofista já deixara claro como vê seus interlocutores: “'ó Sócrates', disse, ‘já com muitos homens entrei em disputa de argumentos ( $\varepsilon^{\prime} \iota \varsigma$ ' $\gamma \hat{\omega} \nu \alpha \lambda \sigma \gamma \omega \nu$ ) e, se tivesse feito o que pedes, se tivesse discutido como o adversário (o

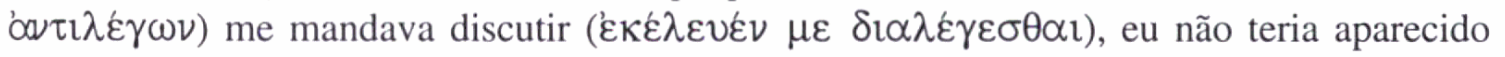

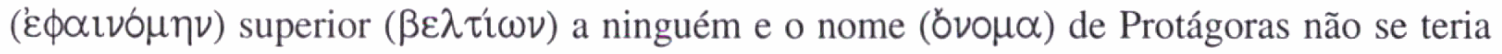

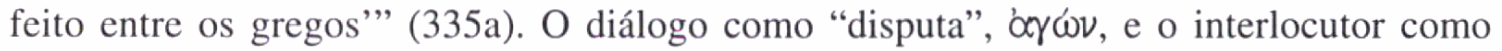
"adversário", ' $\alpha \tau \tau \imath \lambda \dot{\varepsilon} \gamma \omega \nu$; a "superioridade", a fama, o "nome", habitantes daquilo que Sócrates

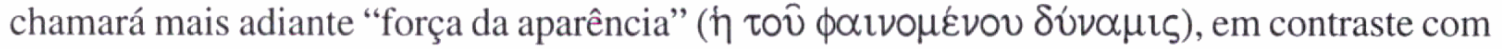

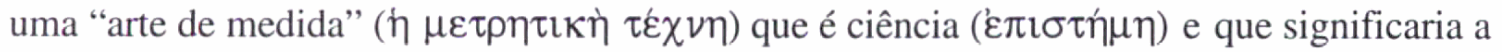
"salvação da vida" (356d): prenuncia-se aí muito das principais preocupações do platonismo maduro. Mas nosso diálogo pretende simplesmente confrontar essa concepção protagoriana

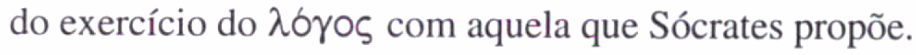


E o que Sócrates propõe não é apenas a primazia do discurso breve ( $\beta \rho \alpha \chi v \lambda \circ \gamma i \alpha$, 335a-b), em detrimento do discurso longo ( $\left.\mu \alpha \kappa p o \lambda \circ \gamma^{\prime} \alpha, 335 b\right)$ de Protágoras. Há muito mais em jogo do que a simples forma do dizer: “ 'Se queres', disse ele (Protágoras), 'discute primeiro essa afirmação, a da maioria'. - 'Ora, para mim (Sócrates) não faz diferença, desde que tu pelo menos respondas, quer assim te pareça quer não ( $\varepsilon ้ \tau^{\prime}$ ’ oరิ

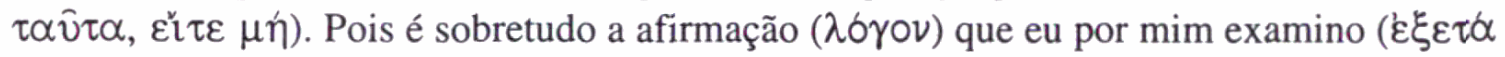
$\zeta \omega$ ), mas sucede talvez que tanto eu que pergunto quanto o que responde ( $\kappa \alpha i \dot{\varepsilon} \varepsilon \mu \dot{\varepsilon} \tau \dot{\nu} \nu$

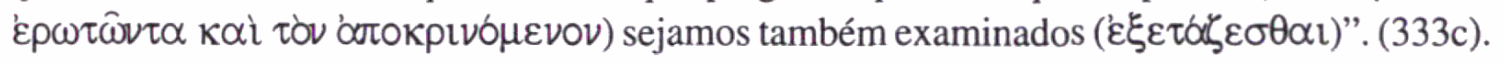
Fazer parte do diálogo, para Sócrates, significa expor-se a ser investigado, aceitar essa possibilidade. Não há, a bem dizer, vitória a ser alcançada, refutação de um adversário, mas sim acompanhamento e, quem sabe, submissão às vicissitudes de um $\lambda \sigma \gamma \circ \zeta$ que, por assim dizer, marchará por conta própria. Tanto é, que sequer importa que Protágoras, ao responder, diga o que realmente pensa: basta que responda, e o próximo passo se apresentará. É o que Hipócrates descobre quando conversa com Sócrates, antes de ir à casa de Cálias. Respondendo a Sócrates que o sofista "sabe tornar hábil no falar", ouve em troca: " 'Talvez', continuei, 'disséssemos a verdade, mas não todavia o suficiente, pois nossa resposta ainda pede uma

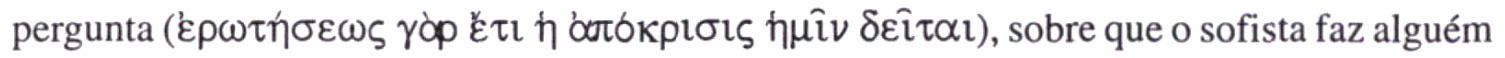

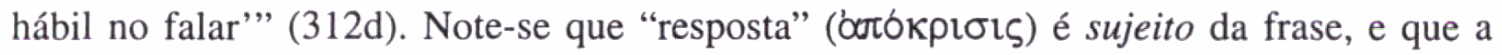
próxima pergunta é pedida - até "exigida" ( $\delta \varepsilon i \tau \propto \alpha)$, pode-se dizer - por ela. Não cabe aos interlocutores determinar o destino da conversação, pois há certo conteúdo que se impõe à sequiência e que deve ser privilegiado, como caminho a ser seguido. É o elemento subjetivo - a importância de quem fala e de seus desejos particulares - que perde aqui espaço, em favor de $o$ que se diz, ditado que é pelo próprio $\lambda \sigma \gamma o \varsigma$ que se desdobra ${ }^{5}$.

Tudo isso está bastante distante do que Protágoras defende, pois o "nome" e a "superioridade" não mais operam, não mais importam. A diferença se expressará em termos mais claros no momento de impasse a que chegará a conversa e que levará Sócrates a anunciar sua saída. Então, respondendo aos apelos dos ouvintes para que fique, Sócrates esclarece: "Se, portanto, desejas ouvir a mim e a Protágoras, pede-lhe que, como antes me respondeu com brevidade ( $\delta \grave{\imath} \beta \rho \alpha \chi \hat{\varepsilon} \omega \nu)$ e às mesmas perguntas, assim também me responda agora;

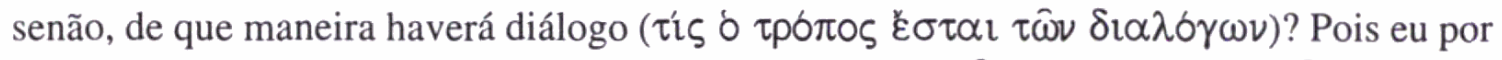

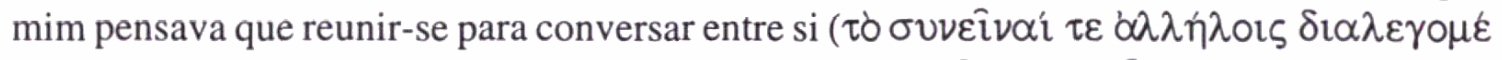

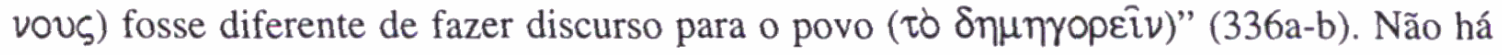

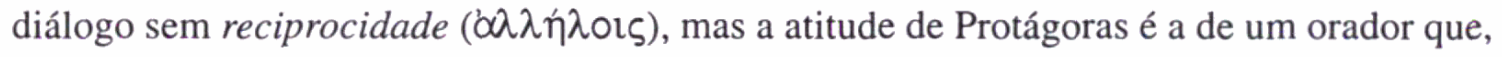
em praça pública, exibe sua técnica a ouvintes passivos e indistintos.

Ora, tais diferenças têm alcance considerável, e caberá à intervenção de Pródico, na tentativa de reconciliar Sócrates e Protágoras, chamar nossa atenção para isso: "belo me parece o que dizes, Crítias; pois os que assistem a tais debates devem ser ouvintes comuns

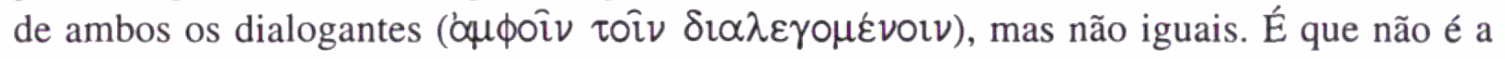
mesma coisa; pois convém ouvir os dois em comum, mas não atribuir a cada o igual e sim, mais ao mais sábio e menos ao mais ignorante. Eu mesmo também, ó Protágoras e Sócrates, peço-lhes que nos concedam e debatam um com o outro sobre as questões, mas não alterquem

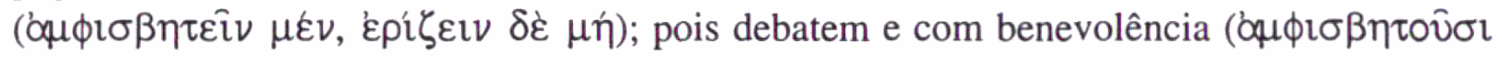

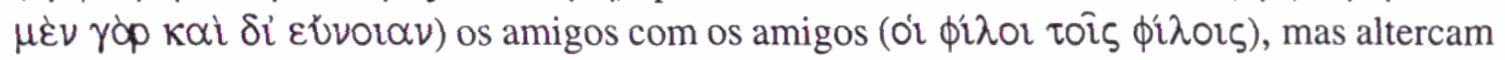




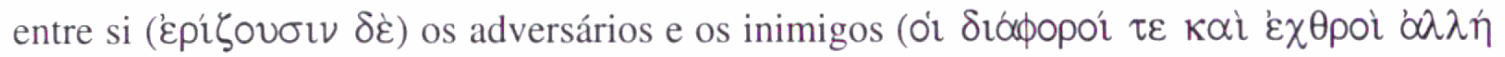

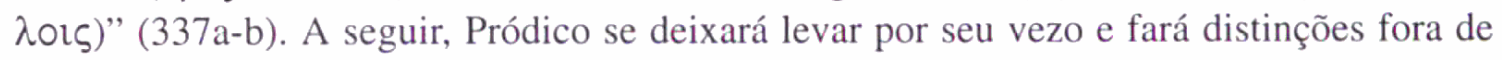
propósito e, ao que tudo indica, inócuas - "aprovação" e "elogio", "alegria" e "prazer". Mas, ao fazer diferença entre "debater" e "altercar", um critério importante se apresenta: a presença ou ausência de $\phi i \lambda i ́ \alpha$ e $\varepsilon$ Uvvoı $\alpha$. Por mais convencional que possa ser a distinção, não devemos ver aí simples verborragia, a não ser que deixemos de lado um aspecto decerto fundamental do socratismo e do platonismo: a dimensão ética do exercício do diálogo e do discurso em geral $^{6}$.

Tudo isso tem, a julgar pelo comentário que Sócrates fará mais tarde, relação íntima com a idéia de $\pi \alpha 1 \delta \varepsilon i \alpha$, pois, para tentar retomar a marcha da argumentação, Sócrates

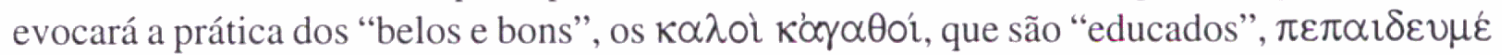

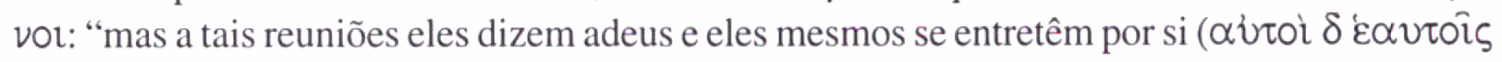

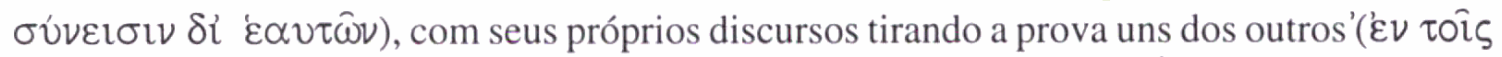

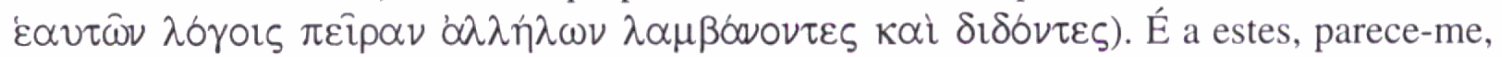
que eu e tu devemos imitar de preferência e, pondo de lado os poetas, conversar entre nós por

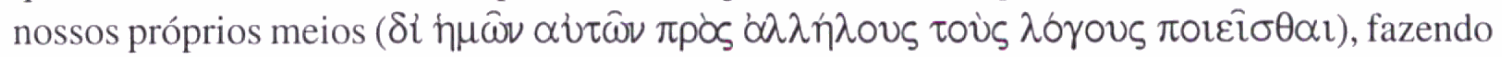

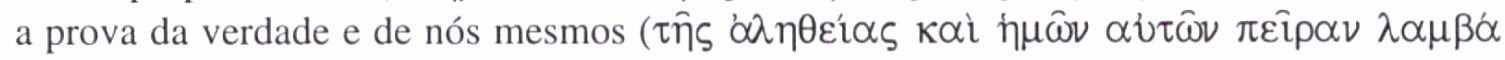

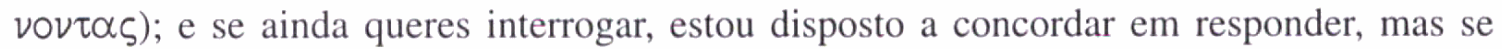
prefere, concorda em que ponhamos termo ( $\tau \varepsilon \lambda \circ \varsigma$ ) naquilo sobre que deixamos de discorrer durante esse intervalo" (347e-348a). Mais uma vez, como em 336b, encontramos o verbo

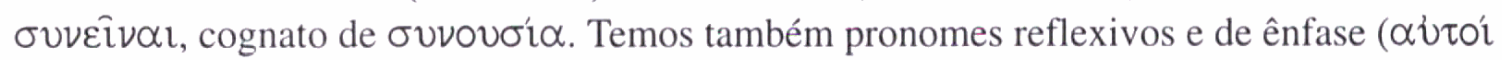

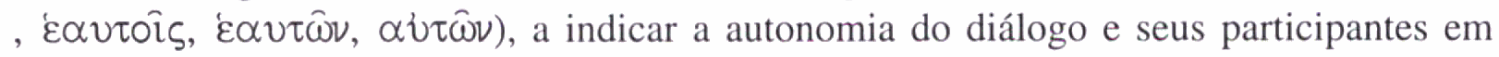

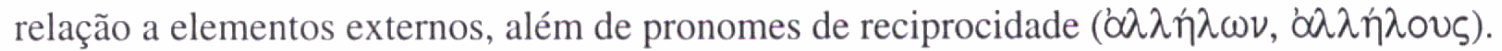
E, literalmente, o que se faz é "tomar e dar prova uns dos outros em ('cv) seus próprios discursos". Nessa passagem, o $\lambda$ ó ${ }^{\circ}$ s não é instrumento, é elemento, o lugar onde se dará a "prova", o "exame" dos envolvidos.

Trata-se de educação, porque, como diz Sócrates, o tipo de diálogo que defende beneficia o agir, o dizer e o pensar: "Protágoras, não penses que eu discuta ( $\delta \mathrm{\imath} \alpha \lambda \varepsilon \gamma \varepsilon \sigma \theta \alpha \mathrm{l})$ contigo com outro propósito senão o de examinar ( $\delta \imath \alpha \sigma \kappa \varepsilon \dot{\varepsilon} \psi \alpha \sigma \theta \alpha \imath)$ questões em que eu mesmo sempre me embaraço ('oropw̄). Pois julgo que Homero diz com muita razão: 'Dois juntos caminhando, um pode antes do outro perceber'. Pois assim mais facilidade ( $\varepsilon \dot{u} \pi \circ p \omega ́$

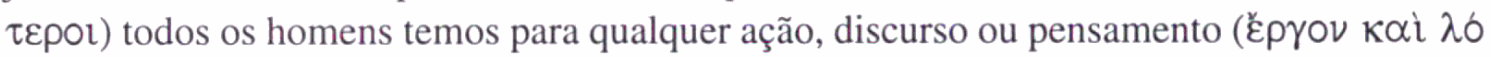

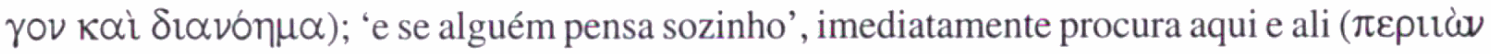
$\zeta \eta \tau \varepsilon \hat{i})$ a quem exponha seu pensamento, com quem se certifique, até que o encontre. Assim

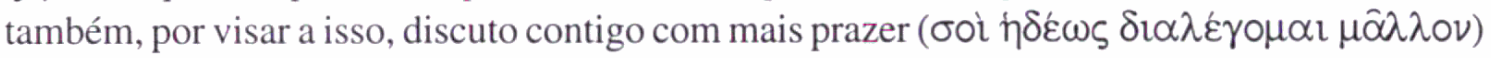
do que com outro qualquer..." (348c-d). Note-se também que, diferente da cena de Protágoras, "prazer" († $\delta \dot{\varepsilon} \omega \varsigma)$, agora, não resulta de ver, mas sim de dialogar?.

A intervenção do anfitrião Cálias também é relevante: “ "não te deixaremos ir, ó

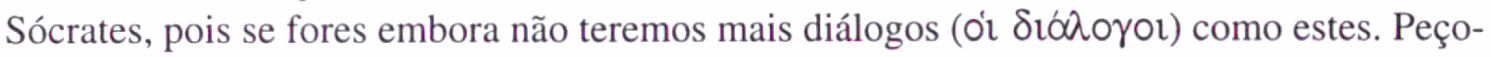
te então que fiques conosco; estou certo de que nada eu ouviria com mais prazer do que uma

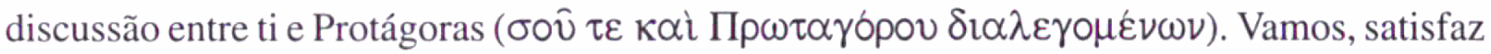
a todos nós"” (335d). Sócrates e Protágoras dialogando juntos - e conjuntos no particípio plural $\delta 1 \alpha \lambda \varepsilon \gamma o \mu \varepsilon v \omega \nu$. Com esse pedido, Cálias provoca em Sócrates o emprego de palavra- 


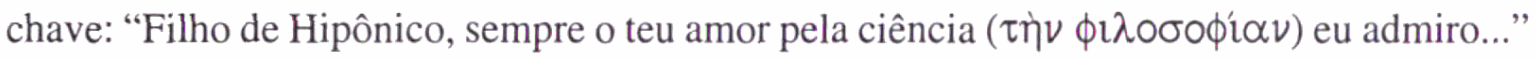
(Ibid.). Não é a única ocorrência do termo no diálogo, mas aqui ele parece ter função primordial: sem expressar conteúdo doutrinal, refere-se ao modo correto, para Sócrates, de exercitar

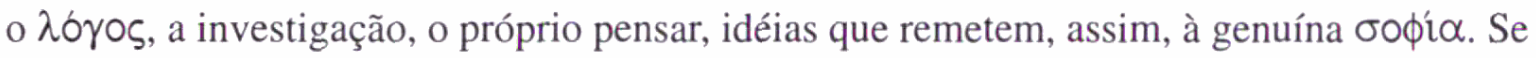
pudermos, então, falar de uma concepção socrática de educação, caberá talvez dizer que, retomando aspectos da tradição, Sócrates por assim dizer os preenche, neste diálogo, com a idéia de "sabedoria", tal como elaborada acima.

O final do diálogo, com Protágoras já irritado, revela em que consiste esse modo de pensar: para saber se a virtude pode ou não ser ensinada, é preciso, antes, saber o que é a

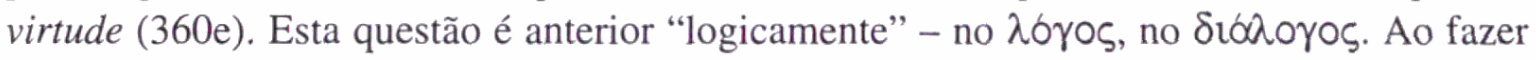
este esclarecimento crucial, Sócrates se refere ao juízo equivocado de Protágoras, a quem dá

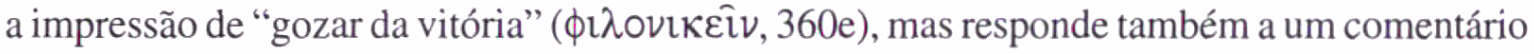
despropositado de Alcibíades, que, quando ocorria o impasse anterior, tentava defendê-lo: "se então Protágoras também admite que é inferior ( $\phi \alpha \nu \lambda \iota_{\tau} \varepsilon \rho \rho$ ) ) a Sócrates no diálogo ( $\delta \imath \alpha \lambda \varepsilon \chi \theta \eta ̄ \nu \alpha \imath)$, é o bastante para Sócrates; mas se ele pretender o contrário, que discuta

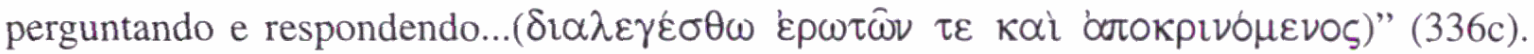
Intervenção que é imediatamente comentada por Crítias: "ó Pródico e Hípias, Cálias me parece estar muito a favor de Protágoras, e Alcibíades é sempre muito apegado à vitória

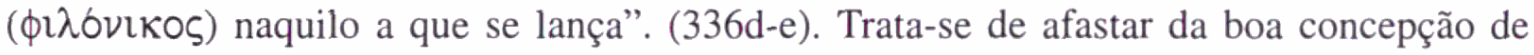
diálogo essa idéia de "vitória", abraçada, como vimos, por Protágoras".

Se vitória deve haver, há de ser do $\lambda$ ó̧os, não dos que o proferem. Eis por que a constatação da inversão de posições entre Sócrates, que defendia de início que a virtude não pode ser ensinada, e Protágoras, que afirmava o contrário, será feita por um $\lambda \sigma \gamma o \varsigma$

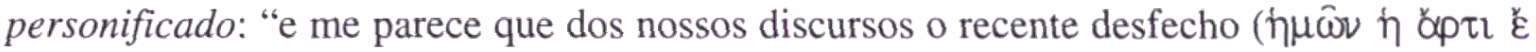
$\xi \circ \delta \circ \varsigma \tau \hat{\omega} \nu \lambda \sigma \gamma \omega \nu)$, como se fosse um homem ( $\omega \sigma \pi \varepsilon \rho$ o $\alpha \nu \rho \omega \pi \circ \varsigma)$, acusa-nos e zomba de

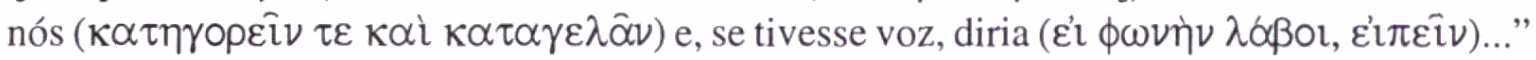
(361a). Eis aí um exemplo do "exame" por que passam os próprios interlocutores.

O Protágoras, então, pode ser lido como uma apologia do diálogo socrático, talvez mais até do que como um seu exercício ${ }^{9}$. E, mais uma vez, o aspecto cênico pode ser evocado. O diálogo se inicia imediatamente após a conversa entre Sócrates e Protágoras, quando o primeiro encontra um amigo anônimo. Informado por Sócrates do ocorrido, o amigo pergunta:

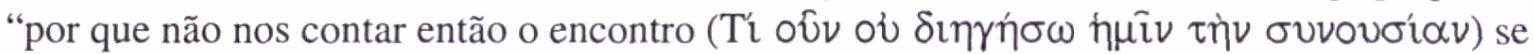
algo não te impede? Manda que este escravo se levante e senta-te aí ( $\kappa \alpha \tau i \zeta o \mu \varepsilon \nu \circ \varsigma$ ' $\varepsilon \nu \tau \alpha \nu \theta^{\prime}$

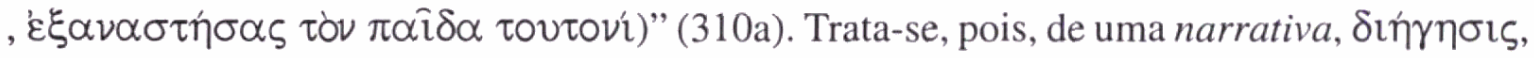
não de diálogo. Como Protágoras na cena aqui destacada, Sócrates fala e sua audiência passivamente o acompanha. Mas, ao contrário do sofista, sua posição espacial será inferior: falará como um escravo, provavelmente aos pés de seus ouvintes, como Hipócrates fizera

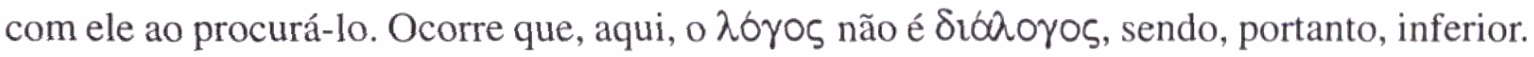
Sócrates deve posicionar-se de acordo com essa inferioridade ${ }^{10}$.

A cena de que partimos, é claro, não precisaria ser como é. Nela, certamente, há muito de pastiche e caricatura, e é isso o que imediatamente se impõe ao leitor, mas não é tudo. $\mathrm{O}$ diálogo contém uma mensagem explícita - a defesa do diálogo, à maneira socrática, contra os expedientes retóricos embutidos no procedimento sofístico -, mas apresenta também, 
subreptícia e simbolicamente, uma outra mensagem, que diz o mesmo, por meio da exploração do elemento cênico e, portanto, eminentemente sensível. Não há por que evitar o termo: nessa cena, como em outros momentos aqui deixados de lado, o que Platão faz chama-se $\pi$ ó

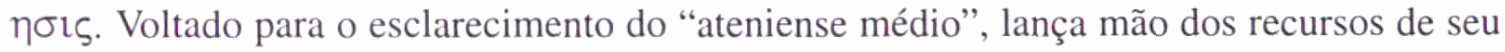
grande talento ${ }^{11}$.

Ao mesmo tempo, a exploração da cena visível se dá norteada pelo que virá a ser a marca registrada do platonismo. Lembremo-nos de que Protágoras e Hípias se destacam aos olhos, enquanto Pródico, simpático a Sócrates, ficava em segundo plano e, por isso, era pouco visível, assim como era pouco audível sua voz. Sócrates, por sua vez, ao apenas narrar o diálogo, coloca-se à vista do leitor em posição sensivelmente inferior. Quanto mais há de

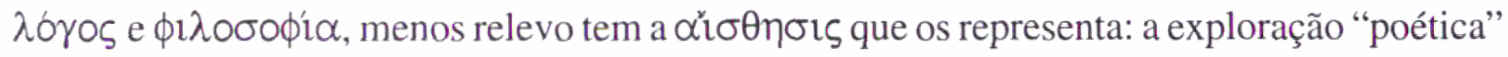
do sensível se desenvolve como uma desvalorização filosófica desse mesmo sensível. Se o Fedro permite pensar a idéia de uma "retórica filosófica", o Protágoras, por seu turno, talvez já houvesse feito algo similar para a róinoıs.

\section{Notas}

* Este texto retoma e desenvolve comunicação apresentada na Semana Platão: Mito e Filosofia, Departamento de Letras Clássicas e Vernáculas, FFLCH - USP, Novembro de 1999.

1 - O pequeno livro de Koyré, introdutório, inspirou um belo texto do professor José Américo Motta Pessanha. Aí, entre outras afirmações relevantes, lê-se: "Ora, se levamos a sério o caráter teatral dramático dos diálogos de Platão, nos sentiremos como que desafiados a aproveitá-lo ao máximo, a fazer muito mais do que o próprio Koyré fez em seu ensaio. Seremos obrigados a esquecer, ainda que temporariamente, o Platão lido através dos prosadores da filosofia, o Platão traduzido, criticado e comentado professoralmente por todos os professores de filosofia ao longo dos séculos, desde Aristóteles, para então resgatar do platonismo alguma coisa que não é apenas o aparato da sua manifestação literária, da sua expressão dialógica e dramática, mas que é o 'o que' nessa expressão é razão de ser dessa expressão. É possível que, ao resgatarmos o sentido dramático dos diálogos, o significado de filosofar para Platão adquira uma outra dimensão para nós. De fato, uma coisa é o Platão vestido prosaicamente em qualquer versão, a mais genial que seja, de Aristóteles a Nietzsche, a Heidegger ou a Lacan. Outra coisa é o Platão respeitado, não como alguém que pensava genialmente e ao mesmo tempo tinha um grande talento que o tornava capaz de vestir o próprio pensamento dessa forma dramática e dialogada, mas como expressando de fato um conteúdo através dessa forma dramática. Ou seja, se nós começarmos a tentar não desvincular a forma do conteúdo e nos dermos conta de que, na filosofia platônica, a forma tem que ser mantida para que o conteúdo seja apreendido e de que a teatralidade e a dramaticidade são fatores inerentes ao pensar filosófico de Platão, talvez consigamos resgatar do platonismo uma outra forma de ler e entender" (Motta Pessanha, 1997, p.1213). Este texto pretende, à sua maneira, experimentar o tipo de leitura sugerida por Koyré e Motta Pessanha.

2 - Será utilizada a tradução de Eleazar Magalhães Teixeira, EUFC, Fortaleza, 1986.

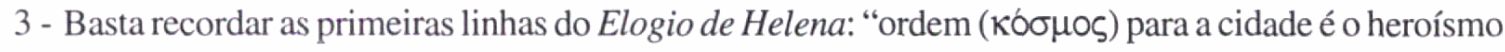
dos homens, para o corpo a beleza, para alma a sabedoria, para o ato a excelência, para o discurso a

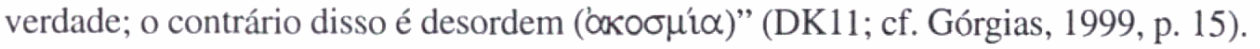


4 - E Pródico, por sua vez, parece conhecer as intenções de Sócrates. Ao menos, é o que sugere sua reação a um pedido de Sócrates para que interrompa suas distinções: "De Pródico aqui solicito que ponha de lado sua distinção dos nomes; pois que o chames de agradável, de prazenteiro ou alegre, ou como quer que te apraza denominar tais distinções, ó excelente Pródico, responde-me isso de acordo com minha intenção. - Rindo ( $\gamma \varepsilon \lambda \alpha \sigma \alpha \varsigma)$ então Pródico concordou..." (358a-b). O sorriso de Pródico não indicaria condescendência amistosa a um companheiro de conversas anteriores? Sócrates chega mesmo a dizer-se discípulo de Pródico (341a), embora, certamente, com alguma intenção de provocar Protágoras.

5 - Outra passagem interessante se encontra em 314c, quando Sócrates e Hipócrates se dirigem à casa de Cálias: "decidido isso, pusemo-nos a caminho. Quando nos encontramos à porta de entrada, paramos e conversamos sobre um assunto que nos ocorreu ao longo do caminho ( $\varepsilon \pi 1 \sigma \tau \alpha^{\prime} \omega \tau \varepsilon \varsigma$

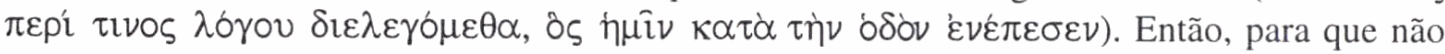

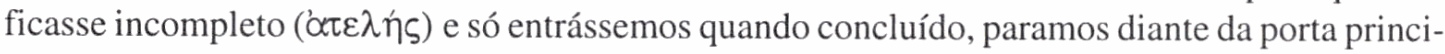

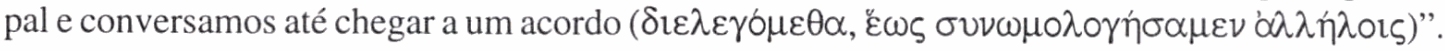

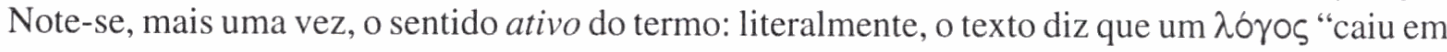
nós no caminho". Sujeito gramatical da frase, o $\lambda$ ó ${ }^{\circ}$ s se impõe e obriga os dois homens a completá-lo, a dar-lhe $\tau \dot{\varepsilon} \lambda \circ \varsigma$. Para isso, é preciso que cheguem a um acordo (literalmente, "até que concordássemos um com o outro"). Não é à toa que o professor Cavalcante, no livro citado, dá a seu capítulo sobre o Protágoras o subtítulo: "A objetividade do $\lambda$ ó $\varsigma^{\circ}$ ". Vale notar, também, seu comentário, noutro texto, a uma afirmação de Sócrates no Teeteto (172b): " Mas quanto a nós, Teodoro, argumento sucede a argumento e, saídos de um menor, um maior nos reclama'. A tradução de A. Diès, fluente e elegante, consegue fazer de 'argumento' (que traduz 'lógos') o sujeito e dos falantes ('nos') o objeto direto, mas de um verbo como 'reclama', que torna visivelmente metafórica a função subjetiva da ação verbal. Na frase grega o verbo é 'katalambánei' (=segura, pega) e é, como na tradução, a última palavra da frase, enquanto a primeira é justamente 'lógos', sem artigo e apoiado no conectivo 'dé' ('mas') que o segue. E assim pictoricamente se impõem o sujeito e sua ação como envolventes. E o que o 'lógos' pega, 'hemâs' (nos), lhe está mimeticamente amalgamado, 'lógos dè hemâs', como a motivar o apelo 'oh Teodoro' e, no segundo conjunto, a qualificação do 'pega' final: 'de lógos menor maior pega'. A função predicativa de 'maior', aclarada numa ágil inflexão sintática, faz com que a frase grega, sem explicitar um devir implícito, nos fale de um lógos único que, no ato mesmo de nos pegar, de menor se torna maior" (Cavalcante de Souza, 1996, p. 53).

6 - Que fique claro que Pródico, aqui, é uma personagem, certamente construída de acordo com as intenções de Platão. Suas distinções podem ter se originado de posição teórica consistente. A respeito de sua possível importância e influência, leia-se o artigo de J. de Romilly (Romilly, 1986). Segundo Romilly, Pródico distinguia as palavras "de maneira empírica e mais ou menos arbitrária", conforme a ocasião, "sem jamais, ao menos nos diálogos de Platão, ultrapassar a intervenção pontual, nem elevar-se a uma análise sistemática ou à definição do conceito comum". É o que Sócrates fará, e esse "é de fato o momento em que a palavra dialética, também ela, muda de sentido: deixando de ser uma arte da discussão, torna-se o que permaneceu sendo, a arte da investigação metódica" (p. 17). Mas Romilly mostrará também a influência do sofista na língua de Tucídides e na de Eurípides.

7 - Quando descrevia a atitude dos "belos e bons", Sócrates dizia também que são bem diferentes dos

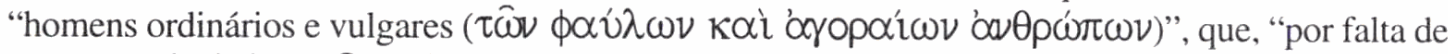

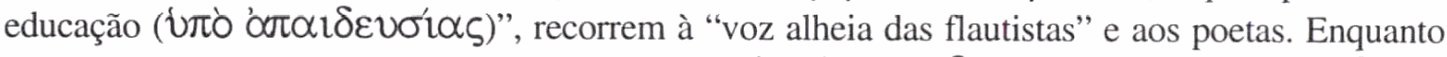

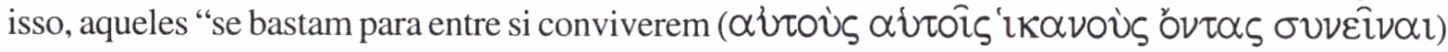
sem as bobagens e brincadeiras delas, falando e ouvindo na vez de cada um ( $\lambda \dot{\varepsilon} \gamma \circ \nu \tau \dot{\alpha} \varsigma \varsigma \tau \kappa \alpha \downarrow$

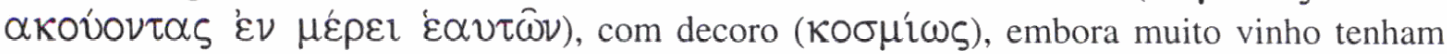


tomado" (347c-d). É certo que se pode ver aí apenas a afirmação dos valores aristocratas, em detrimento dos modos rústicos dos frequientadores da praça pública; mas há também a crítica da poesia como componente educativo das reuniões cultas: não é possível interrogar os poetas sobre o que dizem, o que produz discordâncias sobre o sentido de seus versos entre os que os comentam, os quais acabam "discutindo ( $\delta 1 \alpha \lambda \varepsilon \gamma o ́ \mu \varepsilon v o r)$ sobre assunto que não podem demonstrar" (347e). Também aqui, com este comentário crítico que é sem dúvida tão socrático quanto platônico, está em jogo a função e a própria possibilidade do diálogo, que, neste caso, parece fadado ao fracasso, em virtude de seu próprio assunto. Para tal diagnóstico já apontava, na Apologia, a observação de Sócrates de que os poetas, como os profetas e os adivinhos, não sabem muito bem do que falam (22c). Note-se também que, além do dialogar como causa de "prazer", como vimos, mas de um prazer certamente diferente daquele que o sincronismo dos movimentos produz à visão, pode-se perceber uma função para a noção de $\kappa \delta ́ \sigma \mu ం \zeta$, no sentido, talvez, de ordem e harmonia do próprio dialogar, quando todos falam e ouvem a cada vez. Não seria o adorno, mas talvez a estrutura mesma do correto dialogar o que permitiria repor a expressão, agora devidamente repensada. O que reforça a idéia de que o Sócrates deste diálogo busca apresentar uma alternativa preferível ao ensino do sofista, e isso nos próprios termos deste.

8 - Note-se, porém, que Protágoras chega a penetrar nessa maneira socrática de conceber o diálogo, ao menos numa passagem: " 'Como tu sempre dizes, Sócrates', ponderou, 'examinaremos

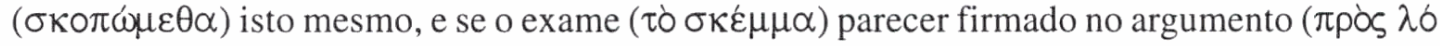
$\gamma \circ \nu . . . \varepsilon i v \alpha 1$ ) e aparecerem ser o mesmo o agradável e o bom, concordaremos ( $\sigma v \gamma \chi \omega p \eta \sigma \delta$

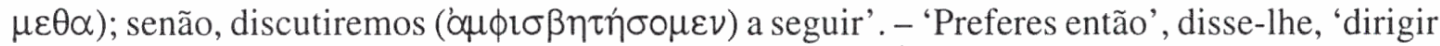

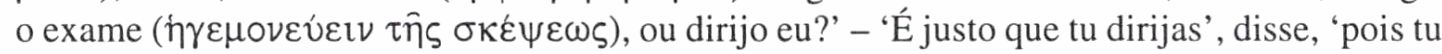

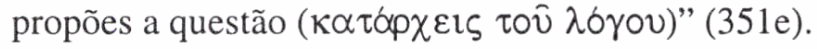

9-Diálogo que o platonismo maduro interiorizará para definir a noção mesma de pensamento: o pensar ( $\tau \dot{b} \delta \iota \propto \nu o \varepsilon i \sigma \theta \propto \imath)$ será "um discurso que a própria alma para si mesma discorre sobre as

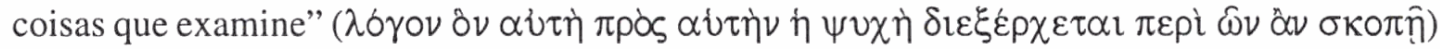

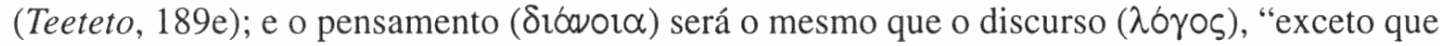

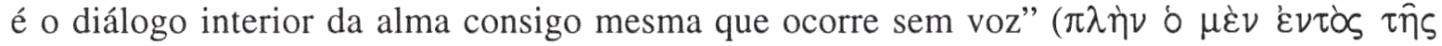

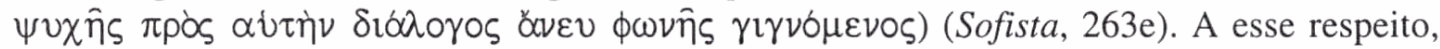
comenta M. Dixsaut: "o diálogo proferido é apenas a tradução fonética de um alternância mais originária - entre se questionar e se responder - que ocorre na alma (pode-se assim compreender por que Platão escreveu diálogos, e que não se trata de uma simples forma retórica, uma maneira de tornar mais dramático e mais agradável o que teria sido pensado de outro modo" (Dixsaut, 1996, p.4).

10 - Não se pretende com isso sustentar que a forma narrativa, por definição, não pudesse ter, para Platão, valor e função positivos na elaboração dos diálogos. Vale lembrar de que Sócrates é narrador em outros diálogos - na República, para citar apenas o maior dos exemplos .... Contudo, no Protágoras, em virtude de seu motivo condutor - contrapor a prática do dialogar, em sentido socrático, aos procedimentos do sofista -, a narrativa, forma de "discurso longo", comparece representando a unilateralidade que se constata na relação entre o sofista e seu ouvinte. Como vimos, disse Sócrates em dado momento, citando Homero, que é preciso que os dois "caminhem juntos" (348d), o que somente o diálogo, socraticamente compreendido, poderá obter, ao afastar a emulação, a busca da vitória etc. Assim, a narrativa - por exemplo, a do mito de Prometeu, mas também a extensa argumentação subseqüente - se mostra, nesse diálogo e nesse contexto, inferior, pois é comparada ao diálogo. Quando Sócrates, no início, se põe a narrar o que sucedeu no encontro com Protágoras, assume um papel numa situação que a sequiência do texto irá caraterizar, já a partir da cena em casa de Cálias, como típica do ensino dos sofistas, situação que poderíamos talvez compreender, em linhas gerais, como de ausência de interlocução, estando já determinado quem detém "saber" e quem dele carece, quem o transmite e quem passivamente 
o recebe. Se assim for, a narrativa poderá ser legítimo recurso em certos diálogos, mas avaliada negativamente em outros. Tudo dependeria de sua função relativa: no primeiro caso, auxilia na busca da verdade; no segundo, exercita uma condenável "ideologia".

11 - "Ele não sai de dentro da poesia para recusar a poesia, mas falando mal de uma certa poesia faz a mais bela prosa poética que sem dúvida a antigüidade produziu. E dentro dessa prosa poética, com todo o direito que a qualidade e o talento de poeta lhe dão, ele condena as outras formas poéticas, ilusionistas, sofísticas." (Motta Pessanha, 1997, p. 20).

\section{Referências bibliográficas}

CAVAlCANTE DE SOUZA, J. Caracterização dos sofistas nos primeiros diálogos de Platão. São Paulo: Universidade de São Paulo, Faculdade de Filosofia, Ciências e Letras, Boletim n. 309, 1969.

Dialogação platônica. Boletim do CPA. Campinas, Ano I, n. 2, julho/dezembro 1996, p. 47-60.

DIXSAUT, M. Qu'appelle-t-on penser selon Platon?. Centre d'études sur la pensée antique "kairos kai logos" (separata). Aix-En Provence: Université de Provence, 1996.

GÓRGIAS. Tratado do não-ente; Elogio de Helena. Trad. Maria Cecília de Miranda N. Coelho. São Paulo: Cadernos de Tradução, Depto. de Filosofia - USP, n. 4, 1999.

KOYRÉ, A. Introdução à leitura de Platão. Lisboa: Editorial Presença/Martins Fontes, 1979.

MOTTA PESSANHA, J. A. Platão - O teatro das idéias. O que nos faz pensar, Depto. de Filosofia da PUC-RIO, n. 11. Vol. 1, Março de 1997, p. 7-35.

PLATÃo. Protágoras. Tradução de Eleazar Magalhães Teixeira. Fortaleza: EUFC, 1986.

PLATÃO. Apologie de Socrate. Texte établi et traduit par M. Croiset. Paris: Les Belles Lettres, 1970.

ROMILLY, J. de. Les manies de Prodicos et la rigueur de la langue grecque. Museum Helveticum. vol. 43, fasc.1, p. 1-18, 1986.

BOLZANI Filho, R. Scenic in Protagoras. Classica, São Paulo, 13/14, p. 219-231, 2000/ 2001.

ABSTRACT: The article intends to examine the function and sense of scenic aspects in some parts of Plato's Protagoras, with the purpose of concluding that such aspects contribute in a decisive way to determining the content of the dialogue.

KEYWORDS: Socratism; Sophistic; dialogue. 